\title{
A cadaveric study on accessory lobes of lungs and their bronchial branching pattern
}

\author{
Biswas K. $\mathbf{K}^{1}$, Mitra $\mathbf{S}^{2}$, Sarma $\mathbf{J}^{3}$ \\ ${ }^{1}$ Dr Krishna Kanta Biswas, Demonstrator, Department of Anatomy, Silchar Medical College and Hospital, Silchar, \\ Assam, India. ${ }^{2}$ Dr. Satyajit Mitra, Associate Professor and HOD (I/c), Department of Anatomy, Gauhati Medical College \\ and Hospital, Guwahati, Assam, India, ${ }^{3}$ Dr. Joydev Sarma, Vice Principal and Professor, Department of Anatomy, \\ Gauhati Medical College and Hospital, Guwahati, Assam, India.
}

Corresponding Author: Dr. Satyajit Mitra, Associate Professor and HOD (I/c), Department of Anatomy, Gauhati Medical College and Hospital, Guwahati, Assam, India. Email: satyajitmitra247@gmail.com

\begin{abstract}
Background: An accessory lobe is a part of lung tissue separated off by an accessory fissure. It develops due to occasional monopodial branching of the stem bronchi. Different accessory lobes may be encountered in the human lungs e.g., azygos lobe, dorsal lobe, cardiac lobe and tracheal lobe. An accessory lobe may be confused with a lung abscess or bulla in x-ray and CT-scan, and its variable bronchial supply may cause difficulty during bronchoscopy. Hence, the present work has been carried out to study the accessory lobes and their bronchial branching pattern in human lungs. Materials and Methods: 92 adult human lungs (46 right and 46 left) were collected from the Department of Anatomy and Department of Forensic and State Medicine, Gauhati Medical College and Hospital, Guwahati, Assam and preserved in $10 \%$ formalin. The lungs were, then, examined for accessory lobes and their bronchial supply was noted following dissection from the hilum. Results: In the present study, the azygos lobes were present in $2.17 \%$ of cases and dorsal lobe was present in $1.08 \%$ of cases, all of which belonged to the right side. The azygos lobes were supplied by the apical segmental bronchus of the right superior lobe and dorsal lobe was supplied by the apical basal segmental bronchus and posterior basal segmental bronchus of the right inferior lobe. Conclusion: A detailed knowledge of the accessory lobes and their bronchial supply is important for correct radiological diagnosis and bronchoscopic examination of lungs.
\end{abstract}

Key words: Accessory lobes, Bronchi, Bronchoscopy, Lungs

\section{Introduction}

An accessory lobe of lung is a part of it, separated off by an accessory fissure, a cleft of variable depth in the lung tissue, lined by visceral pleura [1]. During development, accessory bronchi and lobes of lung develop as a result of occasional monopodial branching of the stem bronchi [2].

Several accessory lobes are described in the literature. When the medial part of the upper lobe of the right lung is separated off by a fissure containing the terminal part of the azygos vein, it is called the 'lobe of the azygos vein' or azygos lobe [3]. The fissure separating the azygos lobe is called the azygos fissure [4]. The azygos fissures may vary in depth and may cut the lateral surface of the lung between the apex and a point two inches below the apex, or may divide the apex of the

\footnotetext{
Manuscript received: $28^{\text {th }}$ December 2017

Reviewed: $7^{\text {th }}$ January 2018

Author Corrected: $14^{\text {th }}$ January 2018

Accepted for Publication: $19^{\text {th }}$ January 2018
}

lung into lateral halves, or may cut off a small tongue shaped lobe from the mediastinal surface of the lung $[3,5]$. The azygos lobes may also vary in size [3]. They develop when the apical bronchus, instead of growing lateral to the arch of the azygos vein, grows medial to it [6]. As a result, the azygos vein lies in the free margin of a mesentery formed by the mediastinal pleura, called the 'mesoazygos' [3,7]. The azygos lobes may also occur on the left side, when a fissure containing the left superior intercostal vein or 'vena azygos minor' is present on the left upper lobe [5].

Among other accessory lobes, a posterior lobe or dorsal lobe may be found in the lung, which is the superior segment of the lower lobe, separated off by the superior accessory fissure, from the basal segments. Sometimes, an inferior accessory lobe or cardiac lobe may be present in the lung, which is the medial basal segment of the lower lobe, separated off by the inferior accessory 


\section{Original Research Article}

fissure, from the rest of the lower lobe [1,8]. Tracheal lobe is the type of accessory lobe, arising from the trachea itself through an accessory bronchus and is located in the upper part of the thorax [9].

An azygos fissure may produce 'tear drop effect' in a chest x-ray, in which the cleft between the 'lobe of the azygos vein' and superior lobe of the lung is represented by a thin line, into which the pleura dipped to enclose the vein [10]. Radiologically, an azygos lobe may be mistaken for a lung abscess or bulla [11].

Knowledge of their bronchial supply also helps in proper therapeutic drainage of secretions from the lungs [7]. Rarely, the azygos lobes may be associated with recurrent hemoptysis without any obvious cause and primary lung carcinoma $[12,13]$.

Moreover, variations of the lung lobes and their bronchial branching may cause difficulties during bronchoscopic examination, and a tracheal bronchus, leading to a tracheal lobe, may cause recurrent respiratory tract infection in infants $[6,14]$.

Hence, the present work has been carried out to study the accessory lobes and their bronchial branching pattern in human lungs.

\section{Materials and Methods}

Type of study: Descriptive study.

Place of study: Department of Anatomy, Gauhati Medical College and Hospital, Guwahati, Assam.
Duration of study: August 2015 to September 2016. Sample size: 92 lungs (46 right and 46 left).

Sample collection: The lungs were collected from the Department of Anatomy and Department of Forensic and State Medicine, Gauhati Medical College and Hospital, Guwahati, after obtaining ethical clearance from the Institutional Ethical Committee.

Inclusion criteria: Adult cadaveric human lungs (aged between 18 and 70 years).

Exclusion criteria: Lungs with previous pathologies, injuries and surgical resections.

Method: After collection, the lungs were washed in running tap water and preserved in $10 \%$ formalin. Lungs were then observed for accessory lobes and their bronchial supply was noted after breaking the surface at the hilum, and scrapping away the alveolar tissues from the bronchi, arteries and veins, following Cunningham's manual of practical anatomy [15].

The lengths of the accessory fissures were measured using a thread and external jaws of a Vernier caliper and their maximum depths were measured using the depth measuring blade of the caliper, and then the average length and depth were calculated.

Statistical methods: Tabulation and analysis of the data was done in Microsoft Excel sheets.

\section{Results}

In the present study, out of 92 lung specimens, the azygos lobes were present in two right lungs (2.17\%) (Table: 1). In all the lungs, the azygos lobes were tongue shaped and separated from the mediastinal surfaces by the azygos fissures (Fig: 1). They were present medial to the superior lobes and superior to the hila of the lungs. In one of the lungs, the azygos lobe was larger than the other. In all the lungs, the azygos lobes reached up to the apices and were supplied by the apical segmental bronchi of the right superior lobes (Fig: 2). The average length of the azygos fissure was $2.74 \mathrm{~cm}$ and average depth (maximum) was $0.58 \mathrm{~cm}$.

Table-1: Incidence of accessory lobes of lungs.

\begin{tabular}{|c|c|c|c|c|}
\hline \multirow{2}{*}{ Lung } & \multicolumn{4}{|c|}{ Accessory lobe } \\
\cline { 2 - 5 } & \multicolumn{2}{|c|}{ Azygos lobe } & \multicolumn{2}{c|}{ Dorsal lobe } \\
\cline { 2 - 5 } & No. of specimens & $\%$ & 1 & $\%$ \\
\hline Right $(\mathrm{n}=46)$ & 2 & 4.35 & 0 & 0 \\
\hline Left $(\mathrm{n}=46)$ & 0 & 0 & No. of specimens & 0 \\
\hline
\end{tabular}

$*_{\mathrm{n}}=$ Total number of specimens on each side. 
Original Research Article

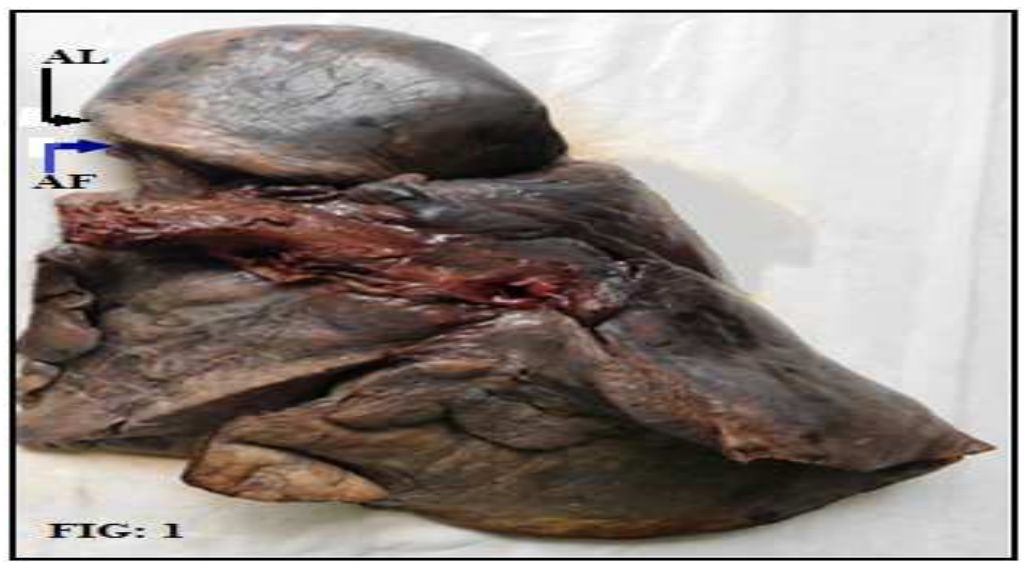

Figure-1: Showing azygos lobe and azygos fissure in the right lung (medial surface).

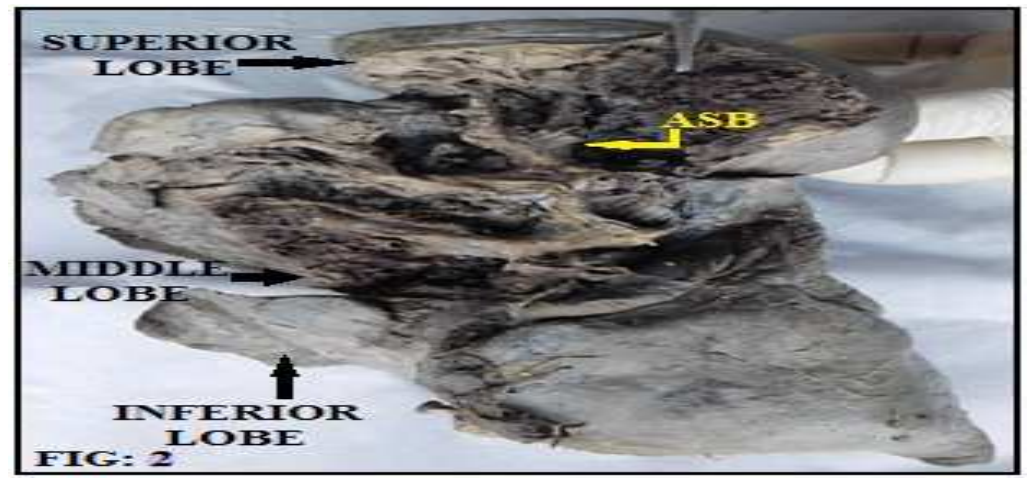

Figure-2: Showing bronchial supply of azygos lobe in the right lung (medial surface).

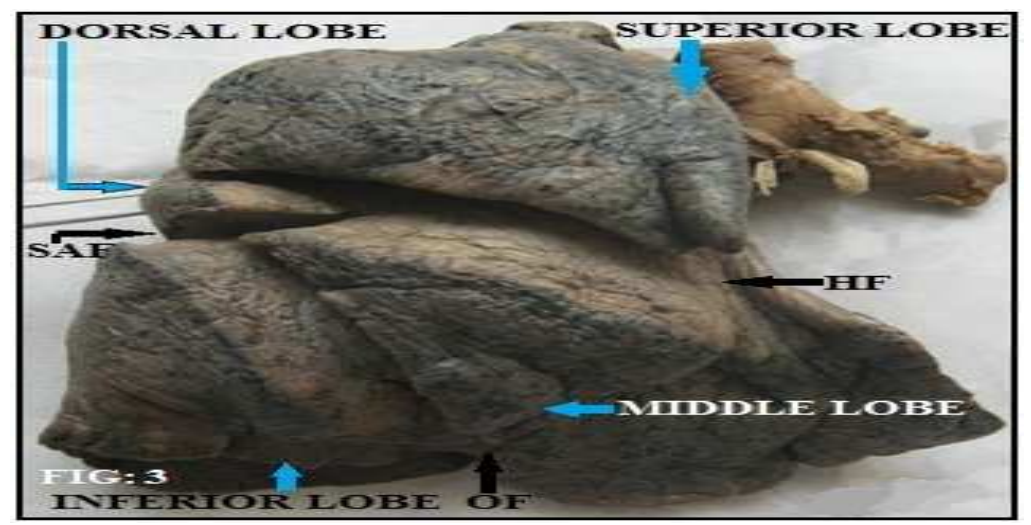

Figure-3: Showing dorsal lobe and superior accessory fissure in the right lung (lateral surface).

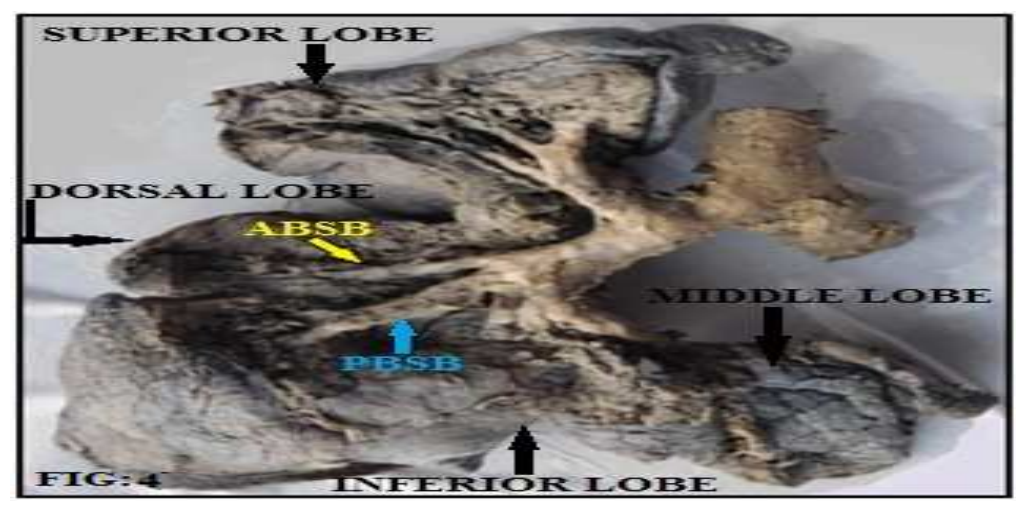

Figure-4: Showing bronchial supply of dorsal lobe in the right lung (lateral surface). 
Moreover, out of 92 lung specimens, the dorsal lobe was present in one right lung (1.08\%) (Table: 1). In this lung, the dorsal lobe was separated from the basal segments of the inferior lobe by the superior accessory fissure (Fig: 3). The length of the superior accessory fissure was $5.58 \mathrm{~cm}$ and depth (maximum) was $1.22 \mathrm{~cm}$. It was supplied by the apical basal segmental bronchus and posterior basal segmental bronchus of the right inferior lobe (Fig: 4).

\section{Discussion}

Several authors have studied the accessory lobes of lungs and their bronchial branching pattern. Mata quoted Boyden and Heitzman in his article [16] as saying that the azygos lobes are present in $1 \%$ of anatomic specimens and $0.4 \%$ of chest radiographs. Rauf et al [17], in a cadaveric study, reported $0.57 \%$ of cases of azygos lobes, while Anson et al [10] reported radiographic incidence of azygos lobes in $0.59 \%$ of cases. Özdemir [18] reported $1.54 \%$ of cases of azygos lobes and Crawford [19] reported $0.11 \%$ of cases of azygos lobes in computed tomographic studies. However, in the present study, the incidence of azygos lobes is higher $(2.17 \%)$ than the previous studies.

Ashwini [20] and Radha [21] reported cases, where the azygos fissures cut the apices of lungs into lateral halves, while Stibbe [5] described cases, where the azygos fissures were present on the lateral surfaces and medial surfaces of the apices of lungs. He also reported a case of azygos lobe, where the azygos fissure was present on the medial surface of the apex of lung, cutting a tongue shaped azygos lobe, which is similar to the case found in the present study.

Bray quoted Wrisberg in his article [22] found that the azygos lobes were present bilaterally, in the cadaver of a three year old boy. Stibbe [5] also mentioned the occurrence of azygos lobes on the left side. However, Takasugi and Godwin [23] reported higher incidence of azygos lobes on the right side as compared to the left side. Rauf et al [17], Ashwini [20] and Radha [21] also reported cases of azygos lobes on the right side. In the present study, all the cases of azygos lobes were present on the right side.

Stibbe quoted Cairney in his article [5] as saying that the azygos lobe was supplied by a branch of the eparterial bronchus, which passed medial to the branches supplying the apex of lung. Kobayashi et al [24], Arakawa et al [7] and Kim et al [25] reported cases, where the azygos lobes were supplied by the anterior and posterior branches of the apical segmental bronchi, while Chiba et al [26] reported a case, where the azygos lobe was supplied by the posterior branch of the apical segmental bronchus and lateral branch of the posterior segmental bronchus. Ndiaye et al [27] reported a case, where the azygos lobe was supplied by the whole posterior branch of the apical segmental bronchus. In the present study, the azygos lobes were supplied by the apical segmental bronchus of the right superior lobe, which is similar to the findings of Kobayashi et al [24], Arakawa et al [7] and Kim et al [25].

Ando T quoted Dévé, Oppenheim and Oguro in his article [28] found that $15 \%$ of cases of dorsal lobes ( $22 \%$ of cases on the right side and $8 \%$ of cases on the left side) were present in an adult European population, $17 \%$ of cases of dorsal lobes ( $15 \%$ of cases on the right side and $19 \%$ of cases on the left side) were present in an adult Chinese population and $6.5 \%$ of cases of dorsal lobes $(10.86 \%$ of cases on the right side and $2.17 \%$ of cases on the left side) were present in an adult Japanese population respectively.

Mawatari et al [29] reported $6.96 \%$ of cases of dorsal lobes $(12.93 \%$ of cases on the right side and $2.55 \%$ of cases on the left side). However, in the present study, the incidence of dorsal lobes is lower $(1.08 \%)$ than the previous studies and all belongs to the right side.

Ando $\mathrm{T}$ also quoted Dévé in his article [28] that there were four types of dorsal lobes, depending on the completeness of accessory fissures, separating the lobes, such as, (a) lower lobe completely separated by the accessory posterior fissure, (b) lower lobe separated incompletely by the accessory posterior fissure connecting with other normal fissures, (c) lower lobe separated incompletely by the accessory posterior fissure, without connection with the normal fissures and (d) lower lobe separated incompletely by the accessory posterior fissure, which exists as a traceable shallow groove. In the present study, the dorsal lobe is incompletely separated by the accessory posterior fissure or superior accessory fissure, which is connected with other normal fissures.

Sreenivasulu et al [30] reported a case of dorsal lobe in the left lung, which was supplied by the apical basal segmental bronchus and posterior basal segmental bronchus. Mawatari et al [29] reported a case, where the dorsal lobe was supplied by the medial basal segmental bronchus forming a common trunk with sub superior bronchus or anterior basal segmental bronchus. The 


\section{Original Research Article}

bronchial supply of the dorsal lobe, in the present study, is similar to the findings of Sreenivasulu et al [30].

\section{Conclusion}

From the present study it can be concluded that, the incidence of the azygos lobes and dorsal lobes of lungs, in the population of Assam, varies with other populations. Moreover, there are few studies on the accessory lobes of lungs and their bronchial branching pattern. Thus, more studies have to be conducted, in this regard, for correct radiological diagnosis and bronchoscopic examination of lungs.

\section{What this study adds to existing knowledge?}

There were no previous anatomical studies on the accessory lobes of lungs and their bronchial branching pattern from the North-Eastern region (Assam) of India. Thus, it will help the radiologists and ENT surgeons of this part of the world to know the different variations of the lobes of lungs and their bronchial supply, and formulate management strategies accordingly.

Contribution by different authors- The study was conducted under able guidance of Dr. Joydev Sarma, Vice Principal and Professor, Department of Anatomy, Gauhati Medical College and Hospital, Guwahati, Assam.

The manuscript was jointly prepared by Dr. Satyajit Mitra, Associate Professor and HOD (i/c), Department of Anatomy, Gauhati Medical College and Hospital, Guwahati, Assam and Dr. Krishna Kanta Biswas, Demonstrator, Department of Anatomy, Silchar Medical College and Hospital, Silchar, Assam.

Abbreviations: Key: $\mathrm{AL}=$ Azygos lobe; $\mathrm{AF}=$ Azygos fissure; $\mathrm{SAF}=$ Superior accessory fissure; $\mathrm{HF}=$ Horizontal fissure; $\mathrm{OF}=$ Oblique fissure; $\mathrm{ASB}=$ Apical segmental bronchus; $\mathrm{ABSB}=$ Apical basal segmental bronchus; $\mathrm{PBSB}=$ Posterior basal segmental bronchus

\section{Funding: Nil, Conflict of interest: None. Permission of IRB: Yes}

\section{References}

1. Godwin JD, Tarver RD. Accessory fissures of the lung. AJR Am J Roentgenol. 1985 Jan;144(1):39-47.

2. Boyd JD, Hamilton WJ, Mossman HW. Alimentary and respiratory system, pleural and peritoneal cavities. In: Prenatal Development of Form and Function Human Embryology. $4^{\text {th }}$ ed. Heffer; 1972. p.330.
3. Standring S. Thorax. In: Gatzoulis MA, editor. Gray's Anatomy The anatomical basis of clinical practice. $40^{\text {th }}$ ed. Edinburgh: Elsevier Churchill Livingstone; 2008. p.992-1006.

4. Muttikkal TJ, Deng C. Non-azygos accessory fissure in right upper lobe associated with superior and inferior accessory fissures in right lower lobe. J Clin Imaging Sci. 2012;2:79. doi: 10.4103/2156-7514.105133. Epub 2012 Dec 27.

5. Stibbe EP. The Accessory Pulmonary Lobe of the Vena Azygos. J Anat. 1919 Jul;53(Pt 4):305-14.

6. Moore KL, Persaud TVN. Respiratory System. In: Clinically Oriented Embryology The Developing Human. $9^{\text {th }}$ ed. Saunders Elsevier; 2013. p.199-210.

7. Arakawa T, Terashima T, Miki A. A human case of an azygos lobe: determining an anatomical basis for its therapeutic postural drainage. Clin Anat. 2008 Sep;21 (6):524-30. doi: 10.1002/ca.20679.

8. Soper WB. Accessory lobes of the human lungs. Trans Am Climatol Clin Assoc [Internet]. 1932 [cited 2017 October 02]; 48 (1):160-8. Available from: https:// www.ncbi.nlm.nih.gov/pmc/articles/PMC2194448/ pdf/ tacca200001-0211.pdf

9. Hollinshead WH. Thorax. In: Anatomy for Surgeons. $2^{\text {nd }}$ ed. Joanna Cotler Books; 1971. p.75-8.

10. Anson BJ, Siekert RG, Richmond TE, Bishop WE. The accessory pulmonary lobe of the azygos vein. Q Bull Northwest Univ Med Sch [Internet]. 1950 [cited 2017 September 29]; 24 (4):285-90. Available from: https://www.ncbi.nlm.nih.gov/pmc/articles/PMC380299 9/pdf/QBullNorthwestUnivMedSch-24-4-285_65.pdf

11. Chabot-Naud A, Rakovich G, Chagnon K, Ouellette D, Beauchamp G. A curious lobe. Can Respir J. 2011 Mar-Apr;18(2):79-80. doi: 10.1155/2011/474678.

12. Denega T, Alkul S, Islam E, Alalawi R. Recurrent hemoptysis- a complication associated with an azygos lobe. The Southwest Respiratory and Critical Care Chronicles. 2015; 3 (11): 44-7. doi: 10.12746/ swrccc 2015. 0311.146.

13. Fukuhara S, Montgomery M, Reyes A. Robotassisted azygos lobectomy for adenocarcinoma arising in an azygos lobe. Interact Cardiovasc Thorac Surg. 2013;16(5):715-7. doi:10.1093/icvts/ivt021. 


\section{Original Research Article}

14. Sadler TW. Respiratory system. In: Langman's Medical Embryology. 12 ${ }^{\text {th }}$ ed. Wolters Kluwer Health Lippincott Williams \& Wilkins; 2012. p.201-7.

15. Romanes GJ. Thorax and abdomen. In: Cunningham's Manual of Practical Anatomy. $15^{\text {th }}$ ed. Oxford: Oxford University Press; 2014. p.33.

16. Mata J, Cáceres J, Alegret X, Coscojuela P, De Marcos JA. Imaging of the azygos lobe: normal anatomy and variations. AJR Am J Roentgenol. 1991; 156 (5):931-7. doi: 10.2214/ajr.156.5.2017954.

17. Rauf A, Rauf WU, Navsa N, Ashraf KT. Azygos lobe in a South African cadaveric population. Clin Anat. 2012 Apr;25(3):386-90. doi: 10.1002/ca.21243. Epub 2011 Jul 28.

18. Özdemir L, Özdemir B, Duman T. Prevalence of an azygos lobe using thoracic computed tomography. Cyprus J Med Sci. 2016;1(1):55-7. doi:10.5152/cjms. 2016.97.

19. Crawford JH. Tomographic appearance of the azygos lobe with a description of two cases and a report of seven cases. Br J Radiol. 1944;17(202):319-22. doi:10.1259/0007-1285-17-202-319.

20. Ashwini H, Archana MH, Jaishree H. Azygos lobe of right lung- a case report. Indian Journal of Medical Case Reports [Internet]. 2013 [cited 2017 December 24]; 2 (3):11-3. Available from: http://www.cibtech. org/jcr.htm

21. Radha K, Duraipandian K. Adams lobe- a case report. J of Evidence Based Med \& Hlthcare [Internet]. 2014 [cited 2017 December 25];1(4):235-7. Available from: https://www.jebmh.com/data_pdf/Radha.pdf

22. Bray G. Two cases of accessory lobe of the azygos vein. Proc R Soc Med [Internet]. 1932 [cited 2016 April 23];26(2):148-9. Available from:https://www. ncbi.nlm. nih.gov/pmc/articles/PMC2204248/pdf/procrsmed0070 8-0082b.pdf
23. Takasugi JE, Godwin JD. Left azygos lobe. Radiology. 1989;171(1):133-4. doi: 10.1148/radiology. 171.1.2928516.

24. Kobayashi T, Satoh K, Kawase Y, Mitani M, Takahashi K, Nakano S, Ohkawa M, Tanabe M. Bronchial and vascular supply in azygos lobe of inflated fixed lung: a case study. Radiat Med [Internet]. 1995 [cited 2016 October 14];13(1):31-3. Available from: https://www.ncbi.nlm.nih.gov/pubmed/7597202

25. Kim WS, Kim MK, Kim SI, Han SR, Jeong O. Azygos lobe of Korean. Korean J Phys Anthropol. 2001;14(4):307-16. doi:10.11637/kjpa.2001.14.4.307.

26. Chiba S, Suzuki T, Takahashi D, Kasai T. An autopsy case of azygos lobe and the extra-pulmonary course of the bronchial veins in man. Okajimas Folia Anat Jpn. 1990;66(6):313-37. doi: 10.2535/ofaj1936. 66.6_313.

27. Ndiaye A, Ndiaye NB, Ndiaye A, Diop M, Ndoye JM, Dia A. The azygos lobe: an unusual anatomical observation with pathological and surgical implications. Anat Sci Int. 2012 Sep;87(3):174-8. doi: 10.1007/s 12565-011-0119-5. Epub 2011 Oct 28.

28. Ando T. Studies on the posterior lobe of the lung in twins. Okajimas Folia Anat Jpn [Internet]. 1951 [cited 2017 November 07]; 23(2):81-94. Available from: https://www.jstage.jst.go.jp/article/ofaj1936/23/2/23_81 /_pdf

29. Mawatari T, Murakami G, Koshino T, Morishita K, Abe T. Posterior pulmonary lobe: segmental and vascular anatomy in human specimens. Clin Anat. 2000; 13 (4): 257-62. doi: 10.1002/1098-2353(2000) 13:4<257::AID-CA5>3.0.CO;2-5.

30. Sreenivasulu K, Anilkumar P, Gaiqwad MR. Morphological anatomy of accessory fissures in lungs. Indian J Tuberc [Internet]. 2012 [cited 2016 June 29]; 59 (1): 28-31. Available from: http://medind. nic. in/ibr/t12/i1/ ibrt12i1p28.pdf

\section{How to cite this article?}

Biswas K. K, Mitra S, Sarma J.A cadaveric study on accessory lobes of lungs and their bronchial branching pattern. Int J Med Res Rev 2018;6(01):18-23. doi:10.17511/ijmrr. 2018.i01.04. 